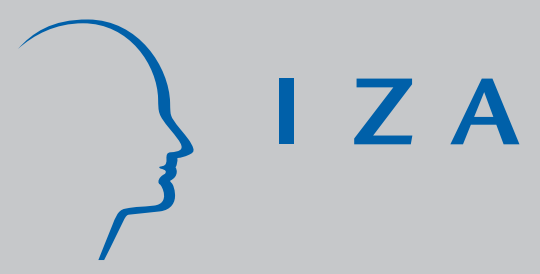

IZADP No. 2851

Modeling International Trade Flows Between Eastern European Countries and OECD Countries

Christophe Rault

Robert Sova

Ana Maria Sova

J une 2007 


\title{
Modeling International Trade Flows Between Eastern European Countries and OECD Countries
}

\author{
Christophe Rault \\ LEO, University of Orleans and IZA \\ Robert Sova \\ CES, Sorbonne University and A.S.E \\ Ana Maria Sova \\ CES, Sorbonne University and A.S.E
}

Discussion Paper No. 2851

June 2007

IZA
P.O. Box 7240
53072 Bonn
Germany

Phone: +49-228-3894-0

Fax: +49-228-3894-180

E-mail: iza@iza.org

\begin{abstract}
Any opinions expressed here are those of the author(s) and not those of the institute. Research disseminated by IZA may include views on policy, but the institute itself takes no institutional policy positions.

The Institute for the Study of Labor (IZA) in Bonn is a local and virtual international research center and a place of communication between science, politics and business. IZA is an independent nonprofit company supported by Deutsche Post World Net. The center is associated with the University of Bonn and offers a stimulating research environment through its research networks, research support, and visitors and doctoral programs. IZA engages in (i) original and internationally competitive research in all fields of labor economics, (ii) development of policy concepts, and (iii) dissemination of research results and concepts to the interested public.
\end{abstract}

IZA Discussion Papers often represent preliminary work and are circulated to encourage discussion. Citation of such a paper should account for its provisional character. A revised version may be available directly from the author. 


\section{ABSTRACT \\ Modeling International Trade Flows Between Eastern European Countries and OECD Countries}

Our paper deals with econometric developments for the estimation of the gravity model which lead to convergent parameter estimates even when a correlation exists between the explanatory variables and the specific unobservable characteristics of each unit. We implement panel data econometric techniques to characterize bilateral trade flows between heterogeneous economies. Our econometric results based on a sample of Eastern European countries (EEC) and OECD countries over a 18 year period highlight the importance of the taking into account of unobservable heterogeneity to obtain a specification in accordance with data properties and unbiased coefficients. The fixed effect factor decomposition (FEVD) technique appears the more suitable for this purpose. We focus more specifically on EEC countries belonging to the last wave of adhesion (Bulgaria and Romania). Since 1990, these countries have moved towards a market economy and more democracy. Our econometric results provide clear evidence in favor of the traditional trade theory based on comparative advantage which suggests a reallocation of labor intensive industry towards EEC generating a complementary specialization.

JEL Classification: F13, F15, C23

Keywords: gravity models, unobserved effects, panel data models, international trade, comparative advantage

Corresponding author:

Christophe Rault

LEO, Université d'Orléans

1 Rue de Blois-B.P.6739

45067 Orléans Cedex 2

France

E-mail:chrault@hotmail.com 


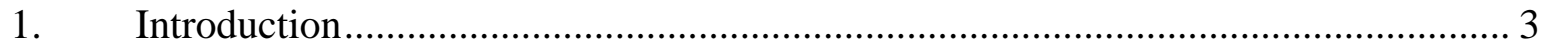

2. An overview of trade flows between EEC and OECD countries ......................... 5

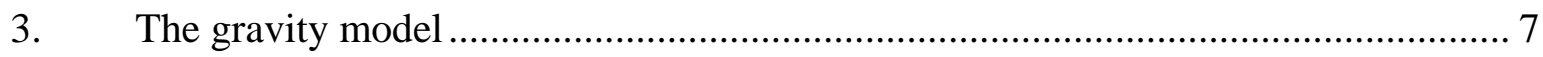

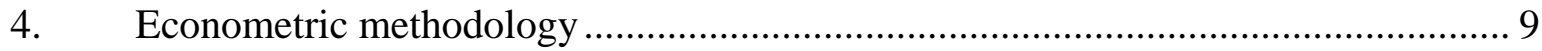

$4.1 \quad$ Pooled Ordinary Least Squares (POLS) ........................................................ 11

$4.2 \quad$ Within estimator and random estimator (FEM and REM) .............................. 11

4.3 The Hausman Taylor method (HT) .................................................................... 13

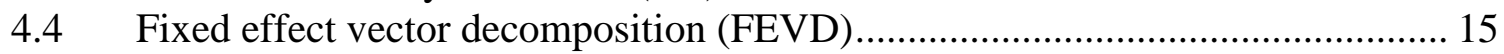

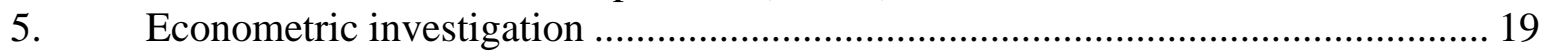

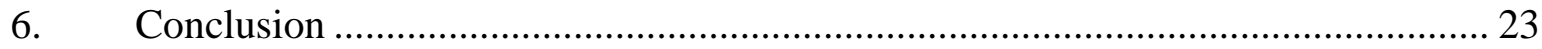

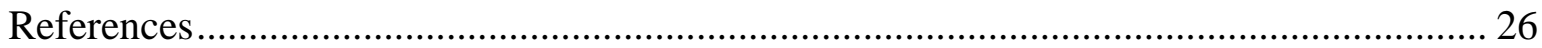

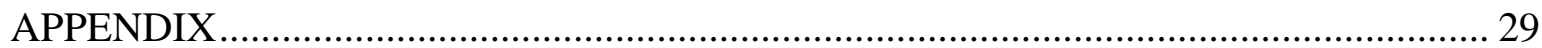




\section{Introduction}

The aim of this paper is to examine and characterize trade relationships between a set of transition and developed countries using recent advances in the econometrics of panel data techniques with fixed effects, which permit to take the unobserved heterogeneity of country behavior over time into account. Our database includes 2 Eastern European countries ${ }^{4}$ (EEC), and 19 OECD countries ${ }^{5}$. Our analysis is motivated by the fact that 15 out of the 19 OECD countries considered are the core of the European Union. In this context an evaluation of the increase of trade flow volume between these two groups of heterogeneous economies and the influence of EU membership represent crucial issues that we address in this study. In our mind this set of heterogeneous economies constitutes a relevant framework worth analyzing.

More specifically, we propose an evaluation of the type of trade and of the specialization degree of economies. In particular, we are interested in determining whether EEC countries continued to specialize in labor intensive industries with their comparative advantage of less expensive labor costs and hence have developed an inter-industry trade, or on the contrary, have generated an intra-industry trade related to an economic convergence. EEC countries aim at reducing their economic development gap and intensifying the convergence process between these two groups of economies ${ }^{6}$ and hence the competition in the area.

But the levels of remunerations in these countries or the gaps in technological level could entail a massive reallocation of labor industries of developed countries towards EEC.

The various theories of international trade permit to release the most relevant ones in the analysis of trade flows between EEC and OECD ${ }^{7}$ countries. Our approach is based on the gravity model which is suitable to the analysis of intra-industry trade and well adapted to

4 Bulgaria, Romania which became new member states of the European Union on January, 2007.

5 EU-15: Austria, Belgium-Luxemburg, Denmark, England, Finland, France, Germany, Greece, Holland , Ireland, Italy, Portugal, Spain, Sweden; non-EU countries : Australia, Canada, Japan, Switzerland, the United States of America.

${ }^{6}$ EEC and OECD countries.

${ }^{7}$ Organization for Economic Cooperation and Development 
the analysis of inter-industry trade. More precisely it allows to characterize the type of trade and hence the specialization at a certain moment.

In international trade the gravity model is widely used as a basic model to estimate the effect of regional agreements, the effect of the monetary union on trade flows and to simulate the trade potential ${ }^{8}$.

The gravity model allows the introduction of a large number of trade flow determinants, the objective being to obtain the best model for the analysis of bilateral trade flows between countries under study. Even if the proposed estimates often remain at an aggregated level, they actually depend on the nature of existing bilateral relationships. Consequently in order to examine the possible existence of a new trade configuration, it appears particularly relevant to us to grant a significant importance to the modeling of heterogeneity behaviors of each couple of countries in trade flows. This can be achieved for instance by the introduction of individual fixed effects, but one can also be willing to take the specific evolution of countries behaviors in time into account through temporal fixed effects (which can capture for example, crises or any other economical or political events $)^{9}$. For all these reasons we find convenient to introduce temporal and couple components (time effects) into our regressions

From an econometric point of view the choice of the econometric methodology is in accordance with the recent developments of panel data methods which explicitly take unobserved heterogeneity into account. In fact, the standard cross-section estimates tend to ignore the unobservable characteristics of bilateral trade relationships (historical, cultural and linguistic links). The existence of a potential correlation between the unobservable characteristics and a subset of the explanatory variables run the risk of obtaining biased estimated (cf. Baltagi, 2001). A possible method to eliminate this correlation relies on the within estimator. In transforming the data into deviations from individuals means, the within estimator provides unbiased and consistent estimates. However, all time invariant variables are eliminated by the data transformation. To overcome this problem, Hausman Taylor (1981), propose an instrumental variable estimator for panel data regression.

\footnotetext{
${ }^{8}$ See for instance Frankel (1997), Wei and Frankel (1998), Bayoumi and Eichengreen (1997), Rose (2000), Matyas (1997), Cheng and Wall (2005), Winters and Soloaga (2001), Baier and Bergstrand (2005), GhoshYamarick (2004), Carrère C. (2006).

${ }^{9}$ See for instance Egger et Pfaffermayr (2003a, 2003b) De Polak (1996), Matyas (1997), Matyas et Haris (1998).
} 
But the Hausman Taylor (HT) method can lead to biased results for small samples. In this case the most appropriate estimator is provided by the fixed effect vector decomposition (FEVD) technique proposed by Plümper and Troeger (2004, 2007).

In the former part of our analysis, we highlight the existence of strong asymmetries in trade relationships between countries of the two groups (OECD and EEC). In the latter we estimate different (alternative) econometric specifications in the line of the gravity model, which enables to emphasize the specificity of bilateral relationships between countries under study. Once the best model (the more congruent with data property) has been chosen, we carefully investigate the main explanatory variables of trade flows between countries. The remainder of the paper is organized as follows. Section 2 presents an overview of the main features of trade exchanges between EEC and OECD countries. Section 3 briefly recalls the theoretical foundations of the gravity model. Section 4 exposes the panel data methodology. Section 5 reports the empirical investigation as well as the econometric results and finally section 5 discusses the policy implications and concludes.

\section{An overview of trade flows between EEC and OECD countries}

The trade pattern of Eastern European countries with regard to OECD remains especially marked by strong asymmetries which result in problems of specialization or of technological gap, and which can play in their disfavor. This constitutes an effect of planned economy heritage which has followed an extensive development policy rather than an intensive one. As now well documented in the literature ${ }^{10}$, Eastern European countries largely directed their trade after 1989 towards Western economies. The economic and political considerations of moving towards democracy have led Eastern European countries to expressed preferences towards Western countries. Until 1989, these countries belonged to planned economies with a trade organization based on the monopoly of international trade, import and export planning and currency inconvertibility. Hence, the trade characteristic was a strong concentration inside the Council for Mutual Economic Assistance (CMEA).

\footnotetext{
${ }^{10}$ See for instance Andreff andAndreff (1995), Maurel and Cheikbossian (1997), Andreff (1998).
} 
But after the fall of the communist regime, these countries gave up their hermetic trade inside CAEM by adopting an open system where Western Europe became one of the most important partners. The economic opening towards Western Europe was very different from one country to another. For instance, in 1989, the trade openness index for Romania was $19.3 \%$, and respectively $18.4 \%$ and $43.2 \%$ for Bulgaria and Hungary. There was an heterogeneity between Central and Eastern European countries in terms of trade openness level.

The reorientation of trade flows towards Western countries is a natural situation in conformity with the gravity model. Consequently, commercial reorientation is rather a reintegration of these countries in the zone. It can be explained by the effect of proximity and also by geographical, historical and even cultural effects which played an important role in the establishment of preferential relationships between the two zones. Before 1990, this reorientation was blocked by the political and ideological context of separation into two parts of Europe.

The reinforcement of the links between Eastern Europe countries and EU coincides with the historical context of EU enlargement.

The evolution of trade flows has followed this tendency of trade reorientation to Western markets, particularly to EU. Brenton (1999) shows that the weight of EU in the CEEC trade (resulting from CAEM disintegration) was relatively similar to the weight of EU in the trade of some of Western European countries like Greece and Spain.

EU countries dominate the trade flows between the two zones (the EEC - EU trade represents almost $90 \%$ from the total trade with 19 OECD countries). We are interested in analyzing the evolution of Eastern European countries' trade configurations following their access to a widened market. An examination of the evolution of trade flows over the 19872004 period should highlight a deep trade gap with respect to EU15.

Since 1990 Romania’s exports to Western Europe have significantly dropped out, but this tendency has reversed after 1993, and they have increased again since the signature of the association agreement with UE15. Their fall after 1989 is due mostly to the reorientation of EU towards Central European countries to which EU have granted trade preferences since 
1991. Since 1992 the trade balance has moved from a trade surplus to a trade deficit. If up to 1996 this deficit was easily negative it has accentuated through time. Indeed, Romania's exports were already directed even during the socialist period towards western countries. An opposite evolution can be observed for Bulgaria. The exports were much lower comparatively with the imports which entailed a permanent deficit in trade balance. Besides, Bulgaria followed an increasing trend of exports and imports with a trade balance in deficit but less accentuated however as during the 1987-1990 period (see the Appendix). For the two countries the increasing tendency of trade is due to external trade liberalization and the opening of their economies to world markets. But the trade liberalization policy of external trade has entailed a rise of imports higher than that of exports.

The pattern changes of exported goods were more complicated because it was conditioned by the speed of the reorganization of the overall economic activity. This is why from a structural point of view external trade is characterized by the existence of labor intensive industries. The less expensive cost of labour ${ }^{11}$ in eastern economies created an advantage for internal products especially for light industry. Romania textile sectors have significantly increased since 1989 , from $19 \%$ to $46 \%$ in 2004 . A similar evolution can be observed for Bulgaria where the same sector has increased since 1989, from 13\% to $36 \%$ in $2004^{12}$.

The strong asymmetries existing between the two groups of countries led us to question about the increase in trade flow volume and also the quality of specializations taking also the logic of integration into account. To shed some light on these issues section 4 proposes an econometric study based on the gravity model, whose foundations are briefly recalled in section 3.

\section{The gravity model}

Our applied modelling is based on the gravity equation which is suitable for the analysis of intra-branch as well as inter/branch trade and permits to define the type of overall trade. For this matter, our analysis is directly in line with recent developments of panel data

\footnotetext{
${ }^{11}$ See Freudenberg (2003) /on average 15\% of EU level.

${ }^{12}$ Graphs are reported in appendix.
} 
methods which enable to explicitly take unobservable heterogeneity into account.

Inspired initially by the law of physics (Newton), the gravity model has become an essential tool in the simulations of international trade flows. The first applications were rather intuitive without substantial theoretical claims. These applications were the object of criticisms concerning the lack of robust theoretical foundations. Among the first studies which have used the gravity model in economic analysis we can note those by Beckerman (1956), Linnemann (1966), Tinbergen (1962) and Poyhonen (1963).

Linnemann explains trade flows between countries $\boldsymbol{i}$ and $\boldsymbol{j}$ and then defines it as a combination of three factors: the offer of the exporter country $\boldsymbol{i}$, the demand of the importer country $\boldsymbol{j}$ and the resistance of trade between countries $\boldsymbol{i}$ and $\boldsymbol{j}$.

The potential offer of the exporter is a positive function of the income level of the exporter country which can be interpreted as a proxy of available good varieties. The potential demand of the importer country also depends positively on the income level of the importer country. In other words, the national incomes of two countries $\boldsymbol{i}$ and $\boldsymbol{j}$, transport costs (transaction costs) and regional agreements are the basic determinants of the model.

Gravity models have received theoretical foundations due to the development of new international trade theories with imperfect competition. Helpman and Krugman (1985) propose a formalization of the gravity equation in which the intra-trade and inter-trade approaches are reconciled.

Bergstrand (1989) model represents an extension of Helpman and Krugman model, taking into account the offer and the demand functions in explaining trade flows. The model also includes a variable of income per capita representing the capital intensity of the exporter country and of the importer country, reflecting a relative factor endowment in terms of GDP per capita. For this author this variable is an indicator of demand sophistication. The required goods may be either luxury or necessity goods. Bergstrand proposes the most complete version of the gravity model using for instance, variables like GDP, GDP per capita, distance, and monetary variables.

The gravity model has been widely used in the applied literature to evaluate the impact of regional agreements, the impact of a monetary union, the impact of Foreign Direct 
investments (FDI) on trade flows, and to simulate the trade potential ${ }^{13}$. After this brief overview of the theoretical foundation of the gravity model, we are now interested in finding the appropriate empirical specification of this model to better characterize the trade flows between countries with a different economic development level (heterogeneous economies), more particularly between CEEC and OECD countries. In the next section we present the econometric methodology which rests upon panel data techniques.

\section{Econometric methodology}

Most studies estimating a gravity model were carried out on cross-section data ${ }^{14}$. Recently several papers have argued that standard cross-section methods lead to biased results because they do not control heterogeneous trading relationships. For instance, the impacts of historical, cultural and linguistic links in trade flows are difficult to observe and to quantify, the presence of minorities, or past memberships in a common trade area can also lead to biased estimates. Panel data regressions allow to correct such effects. The use of panel data is preferred in our analysis because it allows to control specific effects (as fixed or random effects). The source of potential endogeneity bias in gravity model estimations is the unobserved individual heterogeneity.

Matyas (1997) argues that the cross-section approach is affected by a problem of misspecification and consider that a correct econometric specification of gravity model is a “three - way model” with exporter, importer and time effects (random or fixed ones).

Concerning panel data, Egger (2000) mentions that the most appropriate methodology is for disentangling time-invariant and country specific effects.

Egger and Pfaffermayr (2003) indicate that the omission of specific effects per country pair can bias the estimated coefficients. An alternative solution is to use an estimator to control bilateral specific effects like in a fixed effect model (FEM) or in a random effect model (REM).

\footnotetext{
${ }^{13}$ Bayoumi and Eichengreen (1997) note that "the gravity equation has long been the workhorse for empirical studies of the pattern of trade"

${ }^{14}$ See Baldwin (1994), Gros and Gonciarz (1996), Wei and Frankel (1998), Sapir (2001)
} 
However, fixed effect models (FEM) allow for unobserved or misspecified factors that simultaneously explain the trade volume between two countries and lead to unbiased and efficient results ${ }^{15}$.

The choice of the method (FEM or REM) depends on two important things, its economic and econometric relevance. From an economic point of view there are unobservable time invariant random variables, difficult to be quantified, which may simultaneously influence some explanatory variables and trade volume. From an econometric point of view the inclusion of fixed effects is preferable to random effects because the rejection of the null assumption of uncorrelation of the unobservable characteristics with some explanatory variables is less plausible (see Baier and Bergstrand 2005).

Theoretical econometric studies advocate the implementation of Hausman-Taylor's method for panel data incorporating time-invariant variables correlated with bilateral specific effects (see for instance Hausman-Taylor, 1981; Wooldrige, 2002; Hsiao, 2003). As a consequence this method has gained a considerable acceptance among economists (see Egger and Pfaffermayr, 2004).

Recently Plümper and Troeger (2004) have proposed a more efficient method called "the fixed effect vector decomposition (FEVD)" to accommodate time-invariant variables. Using Monte Carlo simulations they compared the performances of the FEVD method to some other existing techniques, such as the fixed effects, or random effects, or HausmanTaylor method. Their results indicate that the most reliable technique is the FEVD if timeinvariant variables and the other variables are correlated with specific effects, which is likely to be the case in our study.

We now briefly present the panel data econometric methods used in our paper to estimate the possible various specifications of our models: pooled ordinary least squares (POLS), random effect estimator (REM), within estimator (FEM), instrumental variables Hausman - Taylor estimator (HT) and fixed effect vector decomposition (FEVD).

\footnotetext{
15 See for instance Matyas 1997, Festoc 1997, Egger 2002, Peridy 2006, Cheng and Wall 2005, Baier and Bergstrand (2005), Ghosh-Yamarick (2004), Carrère C. (2006), Rose (2000), Glick and Rose 2001.
} 


\subsection{Pooled Ordinary Least Squares (POLS)}

The class of models that can be estimated using a pooled ordinary least square estimator can be written as follows

$$
y_{i t}=x_{i t} \beta+z_{i} \alpha+\varepsilon_{i t} \quad \mathrm{i}=1,2, \ldots, \mathrm{N}, \mathrm{t}=1,2, \ldots, \mathrm{T}
$$

, where $\mathrm{y}_{\mathrm{it}}$ is the dependent variable, $\mathrm{x}_{\mathrm{it}}$ are $\mathrm{K}$ regressors not including a constant term. The heterogeneity or individual effect is $z_{i} \alpha$ where $z_{i}$ contains a constant term and a set of individual or group specific variables, which may be observed or unobserved, all of which are taken to be constant over time t.

Ordinary Least Squares (OLS) is often used to estimate the gravity model but does not permit to control the individual heterogeneity and hence may yield biased results due to a correlation between some explanatory variables and some unobservable characteristics. If the Breusch-Pagan test rejects the null hypothesis in favor of random effects, the OLS method is not adequate.

\subsection{Within estimator and random estimator (FEM and REM)}

In the presence of correlation of the unobserved characteristics with some explanatory variables the random effect estimator leads to biased and inconsistent estimates of the parameters. To eliminate this correlation it is possible to use a traditional method called “within estimator or fixed effect estimator" which consists in transforming the data into deviations from individual means. In this case, even if a correlation between unobserved characteristics and some explanatory variables exists, the within estimator may provide unbiased and consistent results.

The fixed effect model can be written as

$$
y_{i t}=\sum_{k=1}^{K} \beta_{k} x_{i t k}+\alpha_{i}+u_{i t}, \mathrm{t}=1,2, \ldots, \mathrm{T}, \quad \mathrm{k}=1,2,, \mathrm{~K} \text { regressors, } \mathrm{i}=1,2, \mathrm{~N} \text { individuals }
$$


, where á denotes individual effects fixed over time and $\mathrm{u}_{\mathrm{it}}$ is the disturbance terms.

$$
y_{i t}-\bar{y}_{i}=\sum_{k=1}^{K} \beta_{k}\left(x_{i t k}-\bar{x}_{i k}\right)+\left(u_{i t}-\bar{u}_{i}\right)
$$

In the fixed effect transformation, the unobserved effect, $a_{i}$, disappears and may lead to unbiased and consistent results.

The random model has the same form as before,

$$
Y_{i t}=\hat{\mathrm{a}}_{0}+\hat{\mathrm{a}}_{1} \mathrm{x}_{\mathrm{it} 1}+\hat{\mathrm{a}}_{2} \mathrm{x}_{\mathrm{it} 2} \ldots \ldots \ldots \ldots \ldots \ldots+\hat{\mathrm{a}}_{\mathrm{k}} \mathrm{x}_{\mathrm{itk}}+\mathrm{a}_{\mathrm{i}}+\mathrm{u}_{\mathrm{it}}
$$

, where an intercept is included so that the unobserved effect, á, has a zero mean. Equation becomes a random effect model when we assume that the unobserved effect á is uncorrelated with each explanatory variable:

$$
\operatorname{Cov}\left(x_{i t k}, a_{\mathrm{i}}\right)=0, t=1,2, \ldots, T ; j=1,2, \ldots, k
$$

The hypothesis mentioned above is actually less plausible and the GLS estimator may lead to biased results.

The Hausman $\left(\mathrm{chi}^{2}\right)$ test consists in testing the null hypothesis of no correlation between unobserved characteristics and some explanatory variables and allows us to make a choice between random estimator and within estimator. The within estimator has however two important limits:

- it may not estimate the time invariant variables that are eliminated by data transformation;

- the fixed effect estimator ignores variations across individuals. The individual's specificities can be correlated or not with the explanatory variable. In traditional methods these correlated variables are replaced with instrumental variables uncorrelated to unobservable characteristics. 


\subsection{The Hausman Taylor method (HT)}

The Hausman and Taylor (1981) ${ }^{16}$ estimator (hereafter HT) overcomes these problems using a method which allows to estimate time-invariant variables and also to consider some explanatory variables included in the model as instruments. In this case the major difficulty of the instrumental method which consists in finding external instruments uncorrelated with unobservable characteristics is avoided.

In HT explanatory variables are divided into four categories: time varying $\left(X_{i t}^{1}\right)$ uncorrelated with individual effects $\alpha_{\mathrm{ij}}$, time varying $\left(X_{i t}^{2}\right)$ correlated with individual effects $\alpha_{\mathrm{i}}$, time-invariant ( $\left.Z_{i}^{1}\right)$ uncorrelated with $\alpha_{\mathrm{i}}$ and time-invariant $\left(Z_{i}^{2}\right)$ correlated with $\alpha_{\mathrm{i}}$. More precisely, the considered equation writes as follows:

$$
Y_{i t}=\beta_{0}+\beta_{1} X_{i t}^{1}+\beta_{2} X_{i t}^{2}+Z_{i}^{1} \gamma_{1}+Z_{i}^{2} \gamma_{2}+\alpha_{i}+\theta_{t}+\eta_{i t}
$$

, where :

- $\beta_{1}, \beta_{2}$, are $\mathrm{k}_{1}, \mathrm{k}_{2}$, vectors of coefficients associated with time-varying and $\gamma_{1}, \gamma_{2}$ are $\mathrm{g}_{1}, \mathrm{~g}_{2}$ vectors of coefficients associated with time-invariant, uncorrelated (index 1) and correlated (index 2) variables respectively;

- $\theta_{t}$ is the time-specific effects common to all cross section units that is used to correct the impact of all the individual invariant determinants (obtained by the inclusion of $\mathrm{T}-1$ dummy variables);

- $\alpha_{j}$ are individuals effects that account for the effect of all possible time invariant determinants, which are assumed to be a time-invariant latent random variable, distributed independently across individuals with variance $\sigma_{\alpha}^{2}$ and that might be correlated with $X_{i t}^{2}$ and/or $Z_{i}^{2}$.

- $\eta_{i t}$ is a zero mean idiosyncratic random disturbance uncorrelated within cross-section units

\footnotetext{
${ }^{16}$ The Hausman -Taylor method relies on a hybrid specification of both the fixed-effect model and the random effect one (see Gardner, 1988).
} 
and over time periods.

The explanatory variables are not correlated with $\eta_{i t}$, even if some of them are correlated with $\alpha_{\mathrm{i}}$. The HT approach consists in using the explanatory variables uncorrelated with $\alpha_{\mathrm{i}}$ as instruments for the correlated explanatory variables.

The $X_{i t}^{2}$ regressors are instrumented by the deviation from individual means (as in the Fixed Effect approach) and the $Z_{i}^{2}$ regressors are instrumented by the individual average of $\mathrm{X}^{1}$ it regressors.The Hausman Taylor estimator allows us to estimate the effect of timeinvariant variables such as distance, common border, and common languages etc... using only internal regressors as instruments.

The (HT) procedure follows 4 steps in the estimation:

(i) Identification of variables $X_{i t}^{1}, Z_{i t}^{1}$ uncorrelated with the unobservable characteristics $\alpha_{\mathrm{i}}$ and $X_{i t}^{2}, Z_{i t}^{2}$ correlated with the unobservable characteristics $\alpha_{\mathrm{i}}$.

(ii) Transformation of variables $X_{i t}^{1}, X_{i t}^{2}$ of the model into deviations from individual means $\Delta\left(\mathrm{X}^{1}\right), \Delta\left(\mathrm{X}^{2}\right)$ and uncorrelated variables $X_{i t}^{1}$ into individual means $\Lambda\left(\mathrm{X}^{1}\right)$. Under the assumption of the absence of correlation between deviations from individual means of varying variables and $\alpha_{\mathrm{i}}$, HT provides unbiased instruments for the $\beta$ coefficients. If the number $k_{1}$ of variables $X_{i t}^{1}$ is equal to or higher than $g_{2}$, then the individual means of $X_{i t}^{1}$ are valid instruments for $Z_{i t}^{2}$ and the HT estimator is then more efficient than the within estimator. The instrument set proposed by HT is $\left[\Delta\left(\mathrm{X}^{1}\right), \Delta\left(\mathrm{X}^{2}\right), \mathrm{Z}^{1}\right.$, $\left.\Lambda\left(\mathrm{X}^{1}\right)\right] 17$ with the condition $k_{1} \geq g_{2}$.

(iii) Selection of instruments. When any variable is of type $Z_{i}^{2}$, we use deviations from individual means of $X_{i t}^{1}$ as instruments, as well as variables $Z_{i}^{1}$. On the other hand, in the presence of $Z_{i}^{2}$ variables, it is necessary to add to the set of instruments individual

\footnotetext{
${ }^{17} \boldsymbol{\Delta}$ is the operator which transforms the variables into deviation from their individual means and $\boldsymbol{\Lambda}$ is the operator which transforms the variables into their individual means.
} 
means of variables $X_{i t}^{1}{ }^{18}$ The HT estimator resulting from this procedure is unbiased, but it is not efficient.

(iv) Improving the efficiency of the estimator. HT suggest to apply the instrumental variable method to the transformed model:

$$
Y_{i t}-\left(1-\phi_{i} Y_{i}\right)=\left[X_{i t}-\left(1-\phi_{i}\right) X_{i}\right] \beta+\phi_{i} Z_{i} \gamma+\phi_{i} \mu_{i}+\left[\eta_{i t}-\left(1-\phi_{i}\right) \eta_{i t}\right]
$$

where :

$$
\phi_{i}=\left(\frac{\sigma_{\eta}^{2}}{\sigma_{\eta}^{2}+T_{i} \sigma_{\alpha}^{2}}\right)^{\frac{1}{2}}
$$

But the model of Hausman -Taylor suffers at least from three serious imperfections: ${ }^{19}$

a) It is very hard to estimate which explanatory variables are likely to be correlated with the unit effects, because the last are unobserved. Unfortunately, the results depend largely on this decision. The best that is possible is to seek specifications which give results close to those obtained by a fixed effect model (FEM).

b) The non-correlated variables should not be adequate instruments for the correlated variables, which can lead to inefficient estimations. The model of HausmanTaylor depends on large samples and consequently is less effective for the small series.

c) In conclusion, we will not have to wait truly impartial evaluations in the presence of the omitted variables what are correlated with both, of the variable dependent and at least of that of the explanatory variables. Procedures as OLS, FEM, REM, Hausman Taylor can largely reduce the bias omitted variables.

\subsection{Fixed effect vector decomposition (FEVD)}

Plümper and. Troeger (2004) suggest an alternative to the estimation of time-invariant

\footnotetext{
${ }^{18}$ If $\mathrm{Z}_{2}$ is empty, the gain obtained by adding individual means of $\mathrm{X}_{1}$ as instruments is marginal (see Martinez-Espineira, 2001).

${ }^{19}$ T. Plümper and V. E. Troeger (2004)
} 
variables in the presence of unit effects. The alternative is a developed model discussed in Hsiao (2003: 52). It is known that unit fixed effects are a vector of the mean effect of omitted variables, including the effect of time-invariant variables. Hence, the unit effects of the FEM contain the vector of time-invariant variables. It is therefore possible to regress the unit effects on the time-invariant variables to obtain approximate estimates for invariant variables. Plümper uses a three stage estimator, where the second stage only aims at the identification of the unobserved parts of the unit effects, and then uses the unexplained part to obtain unbiased POLS estimates of the time-varying and time-invariant variables only at third stage. The unit effect vector is broken into two parts; a part explained by timeinvariant variables and an unexplainable part (the error-term). The model proposed by Plümper and Troeger leads to unbiased and consistent estimates of the effect of timevarying variable and unbiased for time-invariant variables if the unexplained part of unit effects is uncorrelated with time-invariant variables. The estimates of time-invariant variables are consistent only if $\mathrm{N}$ is large otherwise the evaluation of stage 2 is inconsistent. This model adopts the robustness of fixed effect model and allows for the correlation between the time-variant explanatory variables and the unobserved individual effects. In brief, the technique fixed effect vector decomposition (FEVD) proposed by Plümper and Troeger can be summarized by the three following steps:

$>$ estimation of the unit fixed effects by the FEM excluding the time-invariant explanatory variables;

$>$ regression of the fixed effect vector on the time-invariant variables of the original model (by OLS);

re-estimation the original model by pooled OLS (POLS), including all time-variant explanatory variables, time-invariant variables and the unexplained part of the fixed effect vector. Te third stage is required to control the multicolinearity and to adjust the degrees of freedom ${ }^{20}$.

A general form of regression equation can be written as :

\footnotetext{
${ }^{20}$ The program STATA proposed (ado-file) by the authors executes all three steps and adjusts the variancecovariance matrix. Options like Ar (1) error-correction and robust VC matrix are allowed.
} 


$$
y_{i t}=\alpha+\beta X_{i t}+\gamma Z_{i}+\varepsilon_{i t}(8)
$$

where :

$$
\begin{aligned}
& \beta X_{i t}=\text { time-variant variable vector; } \\
& \gamma Z_{i}=\text { time-invariant variable vector; } \\
& \varepsilon_{\mathrm{it}}=\text { normal distributed error component; }
\end{aligned}
$$

In the presence of unobserved time-invariant variables the equation (8) can be written as

$$
y_{i t}=\alpha+\beta X_{i t}+\gamma Z_{i}+u_{i}+\varepsilon_{i t}
$$

where $\mathrm{u}_{\mathrm{i}}=$ unobserved time-invariant variable whose unobserved effects are a random variable rather than an estimated parameter.

In econometric terms, the FEVD technique works as follows.

\section{First step}

Recall the data generating process of the equation (8). The within estimator quasi de-means the data and removes the individual effects $\mathrm{u}_{\mathrm{i}}$ :

$$
y_{i t}-\bar{y}_{i}=\beta_{k} \sum_{k=1}^{K}\left(x_{k i t}-\bar{x}_{k i}\right)+\varepsilon_{i t}-\bar{\varepsilon}_{i} \equiv \tilde{y}_{i t}=\beta_{k} \sum_{k=1}^{K} \tilde{x}_{k i}+\widetilde{\varepsilon}_{i t}
$$

The authors consider that the variance not used by the fixed effect estimator is most important. The unit effects are explained by:

$$
\hat{u}_{i}=\bar{y}_{i}-\hat{\beta}_{k}^{F E M} \sum_{k=1}^{K} \bar{x}_{k i t}=\hat{\alpha}+\gamma_{j} \sum_{j=1}^{J} z_{j i}+\eta_{i}+\overline{\hat{\varepsilon}}_{i}
$$

where :

$\eta_{\mathrm{i}}$ is the unexplained part of the unit effects and $\bar{\varepsilon}_{i}$ are the average unit means of the FEM estimation (indicating panel heteroskedasticity if $\bar{\varepsilon}_{i} \neq 0$ )

\section{Second step}

Given equation (11), it is simple to regress the $\hat{u}_{i}$ on the $\mathrm{z}$-variables. 


$$
\hat{u}_{i}=\omega+\gamma_{j} \sum_{j=1}^{J} z_{j i}+\eta_{i} \text { and } \hat{\eta}_{i}=\hat{u}_{i}-\varpi-\gamma_{j} \sum_{j=1}^{J} z_{j i}
$$

where $\omega$ is the intercept of the stage 2 equation and $\eta_{\mathrm{i}}$ is the unexplained part of the unit effects as in equation (11). Equations (11) and (12) show that if the variables that are simultaneously correlated with the unit-effects $\hat{u}_{i}$ and the time-invariant variables $\mathrm{z}_{\mathrm{i}}$ are excluded the estimates are biased. In other words the estimates are unbiased only if $\eta_{\mathrm{i}} \cong 0$ for all $i$ or if $E\left(z_{i} \mid \eta_{i}\right)=E\left(z_{i}\right)=0$.

\section{Third step}

At the third step, the full model is rerun without the unit effects but including the decomposed unit fixed effect vectors comprising $\hat{\eta}_{i}$ obtained in step 2. Third step is estimated by pooled OLS (or Prais-Winston in the presence of serial correlation).

$$
y_{i t}=\alpha+\beta_{k} \sum_{k=1}^{K} x_{k i t}+\gamma_{j} \sum_{j=1}^{J} z_{j i}+\hat{\eta}_{i}+\varepsilon_{i t}
$$

By construction, $\hat{\eta}_{i}$ is no longer correlated with the vector of the z's.

By including the error term of step 2 it is able to account for individual specific effects that cannot be observed. The coefficient of $\hat{\eta}_{i}$ is either equal to 1.0 or at least close to 1.0 (by accounting for serial correlation or panel heteroskedasticity) at step 3.

Estimating stage 3 by pooled OLS further requires that heteroskedasticity and serial correlation must be eliminated beforehand.

At least in theory this method has three obvious advantages ${ }^{21}$ :

a) the fixed effect vector decomposition does not require prior knowledge of the correlation between time-variant explanatory variables and unit specific effects,

b) the estimator relies on the robustness of the within-transformation and does not need to meet the orthogonality assumptions (for time-variant variables) of random effects,

c) FEVD estimator maintains the efficiency of OLS.

The FEVD is not a perfect estimator, but one of the best available. It produces unbiased estimates of time-varying variables regardless whether they are correlated with unit effects or not and unbiased estimates of time-invariant variables that are not correlated. The

\footnotetext{
${ }^{21}$ T. Plümper and V. E. Troeger (2004)
} 
estimated coefficients of the time-invariable variables correlated with unit effects, however, suffer from omitted variable bias. To summarize, the FEVD produces less biased and more efficient coefficients. The main advantages of the FEVD come from its lack of bias in estimating the coefficients of time-variant variables that are correlated with unit-effects.

\section{Econometric investigation}

We carry out several panel data estimations in order to compare the results across specifications and to identify the most robust one. We first make a test for individual effects and if this confirms their presence, then to control the individual effects we carry out an REM and FEM estimate. To eliminate the unobservable heterogeneity due to bilateral specific effects and avoid the potential bias of the estimators taking the invariant time variables into account it is advisable to use Hausman Taylor and FEVD estimators. Hausman test indicates by the value of $\mathrm{chi}^{2}$ whether the specific effects are correlated or not with the explanatory variables.

The specification retained here to characterize the trade between EEC and OECD countries can be written as follows:

$$
X_{i j t}=e^{a_{0}} G D P_{i t}^{a_{1}} G D P_{j t}^{a_{2}} \operatorname{DGDPT}_{i j t}^{a_{3}} \operatorname{Dist}_{i j}^{a_{4}} \operatorname{Tchr}_{i j t}^{a_{5}} e^{a_{6} A c c_{i j t}} e^{a_{7} C l_{i j}} e^{u_{i j}} e^{\varepsilon_{i j t}}
$$

where :

$>\mathrm{X}_{\mathrm{ij}}$ denotes the bilateral trade between countries $\boldsymbol{i}$ and $\boldsymbol{j}$ at time $\boldsymbol{t}$ with $\mathrm{i} \# \mathrm{j}$ (CHELEM - CEPII French data base);

$>\mathrm{a}_{\mathrm{o}}$ is the intercept;

$>\mathrm{GDP}_{\mathrm{it}}, \mathrm{GDP}_{\mathrm{jt}}$ represents the Gross Domestic Product of country $\boldsymbol{i}$ and country $\boldsymbol{j}$ (CHELEM CEPII - data base)

$>$ DGDPT $_{\mathrm{ijt}}$ is the difference of GDP per capita between partners and is a proxy of economic distance or of comparative advantage intensity,

$$
D G D P T_{i j t}=\left|\frac{G D P_{i t}}{P O P_{i}}-\frac{G D P_{j}}{P O P_{j}}\right|
$$

where $\mathrm{POP}_{\mathrm{i}(\mathrm{j})}$ is the population (CHELEM CEPII data base); 
D Dist $\mathrm{ij}_{\mathrm{ij}}$ represents the distance between two countries, (CEPII data base);

$>\mathrm{Tchr}_{\mathrm{ijt}}$ is the real exchange rate which indicates the competitiveness of price;

$$
T c h r_{i j t}=T c n_{i j t} \times P_{i t} / P_{j t}
$$

where: $\mathrm{Tcn}_{\mathrm{ijt}}$ is the real exchange rate (CHELEM CEPII data base)

$\mathrm{P}_{\mathrm{i}(\mathrm{j})}$ is consumer price index (WORLD BANK - World Tables)

Acc $_{\mathrm{ijt}}$ is a dummy variable that equals 1 if country $\boldsymbol{i}$ and country $\boldsymbol{j}$ have signed a regional agreement, and zero otherwise,

$>\mathrm{Cl}_{\mathrm{ij}}$ is a dummy variable that equals 1 if country $\boldsymbol{i}$ and country $\boldsymbol{j}$ are members of an International Organization (Francophone International Organization), and zero otherwise,

$\varepsilon_{\mathrm{ijt}}$ is the error term, $\mathrm{u}_{\mathrm{ij}}$ is bilateral effect.

After log linearization equation (14) becomes:

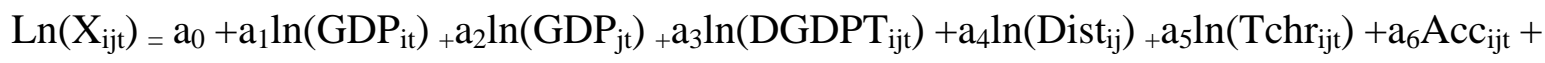
$\mathrm{a}_{7} \mathrm{Cl}_{\mathrm{ij}}+\mathrm{u}_{\mathrm{ij}}+\varepsilon_{\mathrm{ijt}}$

We will show later than the use of a specific effect estimator is more adequate. Indeed, specific effects allow to accommodate unobservable specificities and hence to eliminate the possible source of bias affecting the estimation of some coefficients as it is the case with the OLS method.

The expected signs for the estimators associated with the variables are based on traditional arguments. Theoretically, we expect a positive effect of the variables like the country size, the association agreement, the common language, or the common border on trade flows and a negative impact of the geographical distance and of the real exchange rate. The more the real exchange rate index drops the more there is a depreciation of the exporter currency with respect to the currency of his partner and export competitiveness is improved. Concerning the sign of the difference of GDP per capita, the negative or positive impacts of this variable globally compensates. Generally, it has a positive impact on exports for two very different countries if the Heckscher-Ohlin (H-O) assumptions are empirically 
confirmed. On the contrary, according to the new trade theory, the income per capita variable between countries is expected to have a negative impact. According to the classical theory, an increase in the intensity of the comparative advantages should involve an increase in trade flows. Countries very different in factor endowments and thus, in comparative advantages would exchange more between one another. Geographical distance has always theoretically a negative impact being a proxy of transport costs. Our estimates are organized in a panel with four $\mathrm{EEC}^{22}$ and 19 OECD countries ${ }^{23}$ including EU -15 countries which are the main partners for EEC-2. The data used cover a 18 year period (from 1987 to 2004).

The results of OLS, FEM, REM, HT, FEVD estimations are reported in table $n^{0} .1$ that summarizes the results of our estimations for the whole sample.

Table $\mathbf{n}^{0} 1$

\begin{tabular}{|c|c|c|c|c|c|}
\hline \multirow[t]{3}{*}{ VARIABLES } & OLS & FEM & REM & HT & FEVD \\
\hline & (1) & (2) & (3) & (4) & (5) \\
\hline & xij & xij & xij & xij & xij \\
\hline \multirow{2}{*}{$\mathrm{GDP}_{\text {it }}$} & 0.940 & 1.451 & 1.085 & 1.470 & 1.451 \\
\hline & $(42.29)^{* * *}$ & $(11.08)^{* * *}$ & $(16.78)^{* * *}$ & $(11.54)^{* * *}$ & $(11.08)^{* * *}$ \\
\hline \multirow[t]{2}{*}{$\mathrm{GDP}_{\mathrm{jt}}$} & 0.872 & 1.444 & 1.016 & 1.425 & 1.444 \\
\hline & $(39.26) * * *$ & $(11.03) * * *$ & $(15.71)^{* * *}$ & $(11.18)^{* * *}$ & $(11.03) * * *$ \\
\hline \multirow{2}{*}{ Dist $_{\mathrm{ij}}$} & -1.175 & 0.000 & -1.263 & -1.449 & -1.546 \\
\hline & $(35.70) * * *$ & (.) & $(12.05) * * *$ & $(7.70) * * *$ & $(20.44) * * *$ \\
\hline \multirow[t]{2}{*}{ DGDPT $_{i j t}$} & 0.433 & 0.334 & 0.392 & 0.334 & 0.334 \\
\hline & $(6.22)^{* * *}$ & $(4.42) * * *$ & $(5.38)^{* * *}$ & $(4.42) * * *$ & $(18.64)^{* * *}$ \\
\hline \multirow[t]{2}{*}{$\mathrm{Tchr}_{\mathrm{ijt}}$} & 0.000 & -0.039 & -0.032 & -0.036 & -0.039 \\
\hline & $(0.01)$ & $(2.20)^{* *}$ & $(2.10)^{* *}$ & $(2.10)^{* *}$ & $(2.14)^{* *}$ \\
\hline \multirow[t]{2}{*}{$\mathrm{ACC}_{\mathrm{ijt}}$} & 0.378 & 0.379 & 0.397 & 0.379 & 0.379 \\
\hline & $(17.01)^{* * *}$ & $(20.61) * * *$ & $(22.39) * * *$ & $(20.59) * * *$ & $(21.39) * * *$ \\
\hline \multirow[t]{2}{*}{$\mathrm{Cl}_{\mathrm{ij}}$} & -0.024 & 0.000 & -0.068 & 0.628 & -0.184 \\
\hline & $(0.94)$ & (.) & $(0.79)$ & $(1.21)$ & $(11.94)^{* * *}$ \\
\hline \multirow[t]{2}{*}{ Residuals } & & & & & 1.000 \\
\hline & & & & & $(64.93)^{* * *}$ \\
\hline \multirow[t]{2}{*}{ Constant } & -5.720 & -14.979 & -6.773 & -10.230 & -9.732 \\
\hline & $(20.69) * * *$ & $(14.01)^{* * *}$ & $(11.90)^{* * *}$ & $(9.10)^{* * *}$ & $(160.99)^{* * *}$ \\
\hline Observations & 1368 & 1368 & 1368 & 1368 & 1368 \\
\hline R-squared & 0.74 & 0.54 & 0.74 & - & 0.90 \\
\hline Number of groups & - & 76 & 76 & 76 & - \\
\hline VIF & 1.31 & - & - & - & - \\
\hline $\begin{array}{l}\text { Ramsey-Reset } \\
\text { Prob>F }\end{array}$ & $\begin{array}{l}19.87 \\
(0.00)\end{array}$ & - & - & - & - \\
\hline $\begin{array}{l}\text { White's test (before correction) } \\
\text { Prob>chi2 }\end{array}$ & $\begin{array}{r}148.67 \\
(0.00)\end{array}$ & - & - & - & - \\
\hline
\end{tabular}

22 Bulgaria, Romania

${ }^{23}$ EU-15: Austria, Belgium-Luxemburg, Denmark, England, Finland, France, Germany, Greece, Holland , Ireland, Italy, Portugal, Spain, Sweden; non-EU countries : Australia, Canada, Japan, Switzerland, the United States of America. 


\begin{tabular}{|l|c|c|c|c|c|}
\hline $\begin{array}{l}\text { Fischer test for individuals } \\
\text { effects }\end{array}$ & - & - & $\begin{array}{c}27.54 \\
(0.00)\end{array}$ & - & - \\
\hline Fischer test for time effects & - & - & $\begin{array}{c}27.72 \\
(0.00)\end{array}$ & - & - \\
\hline Hausman test & - & - & - & 20.73 & - \\
& & & $0.00)$ & \\
\hline
\end{tabular}

A comparison between the five estimations leads to the following conclusion.

In all the estimations we can note that the variable of income per capita has the expected positive sign which is in accordance with the H-O theory, i.e. the trade between two zones is based on comparative advantage. It's a complementary inter-industry trade where less developed countries are specialized in labor intensive industries and where wage costs are less expensive. But, the coefficient is low (0.334) and it implies that inter-industry trade is reduced in favor of vertical intra-industry trade, which concerns the multinational strategies of production development on segments of quality. Moreover, there is an access to a larger market, the more the volume of trade flows increase (according to the coefficient of the size of the importer country). The variables like country size, difference of incomes per capita, which have the most important coefficients explain better the level of bilateral exchanges. The international organization membership has a low influence on trade flows. On the contrary, the distance variable (proxy costs of transport) represents an obstacle for trade. It should be noted that the distance between countries has an important elasticity and hence has an important explanatory capacity. The elasticity of the geographical distance is systematically high, close to (-1.5), indicating that trade flows are extremely sensitive to transport costs. However the impact of the geographical distance remains high, which means that technical improvements (communications, modern transports) did not improve international trade.

The results of the random estimator are different from those obtained with the within estimator, for some explanatory variables. This means that there exists a correlation between some of the explanatory variables and the bilateral specific effect. Moreover, the Hausman test confirms the presence of a correlation and rejects the null assumption of absence of a correlation between the individual effects and explanatory variables. Random estimate is biased, and in this case the use of Hausman-Taylor instrumental variables methods (1981) to correct the bias is justified. Using HT we obtain some similar 
coefficients to FEM. We note that the coefficient of the distance is higher than the other estimate but is in accordance with other papers ${ }^{24 .}$ The results for FEVD are similar to those obtained by within which confirm the robustness of the estimation but also we highlight, like in HT method, the time - invariant variables and their important influence on the trade flows. In our case, the last method is more appropriate taking the size of our sample into account, the value of $\mathrm{R}^{2}=0.90$.

\section{Conclusion}

In this paper we have investigated trade flows between EEC and OECD countries using recent developments of panel data techniques with fixed effects which permit to control the individual heterogeneity and hence to avoid biased results. Indeed, it is now well known that the use of conventional time-series and cross-section methods do not allow to control unobservable heterogeneity and hence are likely to produce biased results ${ }^{25}$. Our empirical results enable us to draw the following conclusions:

(i) From an econometric point of view the use of FEVD method to estimate the gravity model appears the most convenient for our study. More particularly in the presence of a correlation between some explanatory variables and the unobserved characteristics (here the unobserved bilateral effect) this method produces consistent parameter estimates contrary to the GLS method. Besides, in contrast to the standard within estimator the FEVD method allows to derive parameter estimates for time invariant variables (such as geographic distance, the common border, the common language,...). In this case the FEVD method is more appropriate if we take the size of the sample into account.

Our econometric estimations reveal that the country size and geographical distance variables have a crucial impact in the international trade flow explanation and are the most important sources of this correlation.

(ii) From an economic point of view trade flows existing between EEC and OECD countries, that is, two sets of heterogeneous economies with different levels of economic

\footnotetext{
${ }^{24}$ See Peter Egger (2000).

${ }^{25}$ See Badi H. Baltagi (2001)
} 
developments are inter-industry and vertical intra-industry trades. The vertical intraindustry trade was stimulated by the multinational firms which developed in EEC countries a labor intensive production segment due to their comparative advantage and their less expensive labor costs than in developed countries. The positive coefficient of the DGDPT variable which represents a proxy of comparative advantage intensity emphasized that the economic distance between OECD and EEC countries constitutes the specialization determinant of these countries on various branches according to their comparative advantages (inter-industry trade), as well as on some qualitative segments within these branches (vertical intra-industry trade). Similar results are obtained by Andreff (1998) who finds that highly exported products by EU with comparative advantages for them are products incorporating medium or high technology and high added value. On the contrary, products highly imported by EU or with comparative disadvantages for them belong to CEEC traditional sectors, and are intensive in labor or in raw materials. The author comes to the conclusion "that there are no statistically significant modifications of trade flows between EU and CEEC neither in terms of product structures nor in terms of intra-branch trade ".

But these types of trade do not actually lead to convergence, the main goal of Central and Eastern European countries. Indeed, economic convergence is associated rather to a horizontal intra-industry trade which assumes the existence of simultaneous exports and import flows of comparable sizes inside the same branch, that is similar products of the same quality, of the same technology and an important added value. Consequently horizontal intra-industry trade is an indicator of the convergence degree between countries. However this type of trade is less developed between EEC and OECD countries and the tendency to an economic convergence is less optimist for EEC countries in the short run since no competition exists but only complementary market segments. In fact, trade flows are essentially stimulated by price competitiveness.

Finally, variables such as partner size, economic distance, or agreement membership have the highest (significant) coefficients in our regression, and hence explain better the level of bilateral trade as well as the attraction between partners for a deeper integration. On the contrary the distance variable plays as a rejecting factor. The other variables have a low explanatory power. A positive and significant effect of economic distance which can be 
attributed to a traditional trade explanation (inter/industrial trade is favored by differences in factorial endowments) is highlighted. In addition the importance of using a model in accordance with data properties clearly emerged from our investigation. The choice of an unbiased estimator and the variable definition is also of crucial importance. 


\section{References}

[1] Aitken, "The effect of the EEC and EFTA on European trade: a temporal cross-section analysis “, American Economic Review, 63(5), 1973

[2] Baier, L.S., Bergstrand, J.H, "Do Free Trade Agreements Actually increase Members' International Trade?”, FRB of Atlanta Working Paper No. 2005-3., 2005

[3] Balassa B., "European Economic Integration”, North Holland, Oxford, 1975.

[4 Baldwin R.E., “Towards an Integrated Europe”, London, CEPR, 1994.

[5] Bayoumi T., Eichengreen B., "Is regionalism simply a diversion? Evidence from the evolution of the EC and EFTA", NBER Working Paper, 5283,1997

[6] Baltagi B.H., "Econometric Analysis of Panel Data”, John Wiley \& Sons Ltd, New York, 2nd edition.,2001

[7] Bergstrand J.H., "The Gravity Equation in International Trade: some Microeconomic Foundations and Empirical Evidence", The Review of Economics and Statistics, Vol. 67, No 3, August, pp. 474-481., 1985

[8] Breuss F., Egger P., "The Use And Misuse Of Gravity Equations In European Integration Research”, WIFO Working Paper, No. 97-03, 1997

[9] Carrere C.," Revisiting the Effects of Regional Trading Agreements on Trade Flows with Proper Specification of Gravity Model”, European Economic Review vol. 50, 223247, 2006

[10] Cheng I.-H.,Wall, H. Controlling for heterogeneity in gravity models of trade and integration, Federal Reserve Bank of Saint Louis Review 87, 49-63., 2005

[11] Egger P., "A note on the Proper Econometric Specification of the Gravity Equation”, Economics Letters, Vol. 66, pp.25-31,2000

[12] Egger,P., "An Econometric View on the Estimation of Gravity Models and the Calculation of Trade Potentials", The World Economy 25 (2), 297 - 312,2002

[13] Egger, P., and Pfaffermayr, M., "Structural Funds, EU Enlargement, and the Redistribution of FDI in Europe “,WIFO Working Papers, Nr. 195, 2003.

[14] Eichengreen, B, and Irwin, D.A.,"Trade Blocks, Currency Blocks and the Desintegration of World Trade in the 1930s”, Journal of International Economies vol 38, No 1,2 Février , pages 1-25.,1995 
[15] Evenett, S.J. and Keller, W. “On Theories Explaining the Success of the Gravity Equation.” Journal of Political Economy 110(2002): 281-316.

[16] Frankel, J., "Regional trading blocs in the world economic system”, Institute for International Economics, Washington, 1997

[17] Frankel. J, Jeffrey A., Stein E., Wei S.J., “Trading Blocs and Americas: The Natural, the Unnatural, and the Super-natural”, Journal of Development Economics 47, no.1: 61-95., June 1995.

[18] Festoc F., “Le potentiel de croissance du commerce des pays d’Europe Centrale et Orientale avec la France et ses principaux partenaires”, Economie et Prévision., $n^{\circ} 218,1997$

[19] Ghosh S., Yamarik S., “Are Regional Trading Arrangements Trade Creating?: An Aplication of Extreme Bounds Analysis.”, Journal of International Economics 63, no.2: 369-395., July 2004

[20] Glick, Reuven \& Rose, Andrew K., "Does a currency union affect trade? The time-series evidence," European Economic Review, Elsevier, vol. 46(6), pages 1125-1151, June 2002

[21] Gros D., and Gonciarz,A., “A Note on The Trade Potential of Central and Eastern Europe”, European Journal of Political Economy, Vol.12, pp 709-721, 1996.

[22] Hausman J.A. and Taylor,W.E.,1981), “Panel Data and Unobservable Individual Effects”,Économetrica, 49, pp. 1377-1398,1981.

[23] Helpman, E. and Krugman, P., “Market Structure and Foreign Trade. Increasing Returns, Imperfect Competition, and the International Economy”, Cambridge MA/ London: MIT Pres. 1985.

[24] Linnemann, H., “An Econometric Study of International Trade Flows”, North Holland Publishing Company, Amsterdam, 1966.

[25] Matyas, L., “Proper Econometric Specification of the Gravity Model”, The World Economie, 20 (3), 363-368, 1997

[26] Péridy. N., « La nouvelle politique de voisinage de l’Union européenne,ne estimation des potentiels de commerce',Revue économique ,4 (Vol. 57)| ISSN 0035-2764 | ISSN numérique : en cours | ISBN : 2-7246-3037-8 | page 727 à 746, 2006 [27] Plumper, T. and V. Troeger (2004), “The Estimation of Time-Invariant Variables in Panel Analysis with Unit Fixed Effects,” Konstanz University, mimeo. 
[28] Plumper, T. and V. Troeger (2007), « Efficient Estimation of Time-Invariant and Rarely Changing Variables in Finite Sample Panel Analyses with Unit Fixed Effects”, Political Analysis, April; 15(2): 124 - 139.

[29 ] Rose, Andrew K. “One Money One Market,” Economic Policy 15-30, 7-46, 2000.

[30] Sapir A., Winter C., "Services Trade”, Surveys in International Trade, edited by David Greenaway and L. Alan Winters, Oxford, UK: Blackwell, 1994.

[31] Soloaga, I. y L. Winters (2001). "Regionalism in the Nineties: What Effect on rade?”, North American Journal of Economics and Finance, 12: 1-29. (También en manuscrito del Grupo de Desarrollo Económico del Banco Mundial),2001

[32] Sova A., Sova, R., "Le commerce international dans les conditions de l'intégration européenne », Romanian Statistical Review, No 12. p.79-86, 2006

[33] Wei, S.J, and Frankel, J.A., "Open Regionalism in a World of Continental Trade Blocs," IMF ... International Monetary Fund, vol. 45(3), pages 2, 1998 ...

[34] Wooldrige, J.H., "Introductory Econometrics: A Modern Approach, 3rd Edition”, Thomson South-Western, ISBN 0-324-28978-2.2005

[35] Wooldrige, J.H., "Econometric Analysis of Cross Section and Panel Data 2rd Edition”: Books: The MIT Press Cambridge, Massachusetts London, England,, 2002. 


\section{APPENDIX}

\section{Graph $\mathrm{n}^{0}$ 1: Evolution of the exports and imports of Romania and Bulgaria}

(in \%) $1987 \rightarrow 2004$
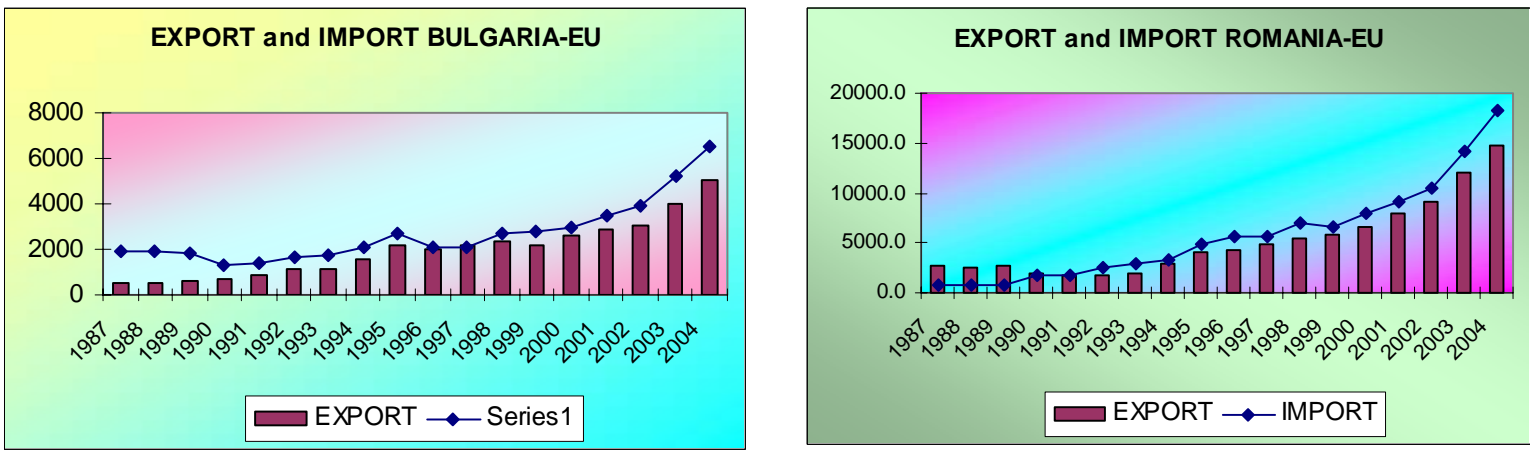

Romania's exports have experienced a decrease up to 2679.8 million USD in 1991 and then a restarting and a significant growth up to 4768.6 in 2004. On the contrary, imports have regularly grown up to 805.9 in 1989, reaching a maximum of 18185.9 in 2004. (Graph 1).

Graph $n^{\circ}$ 2: Variation of the exports and imports of Romania and Bulgaria (in \%) $1987 \rightarrow 2004$
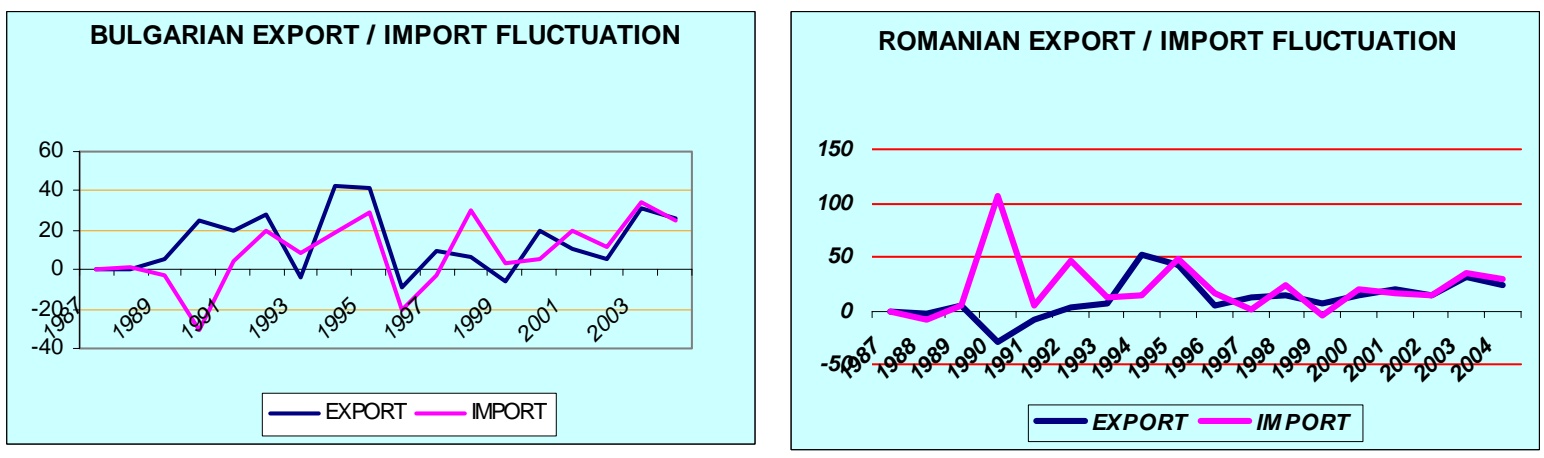

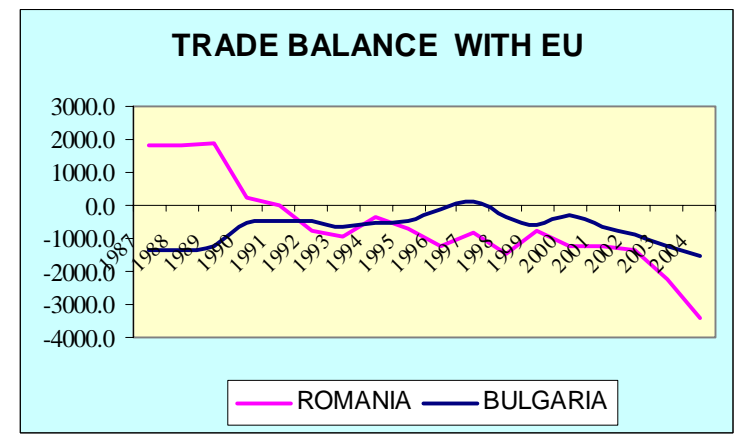

Trade balance with EU

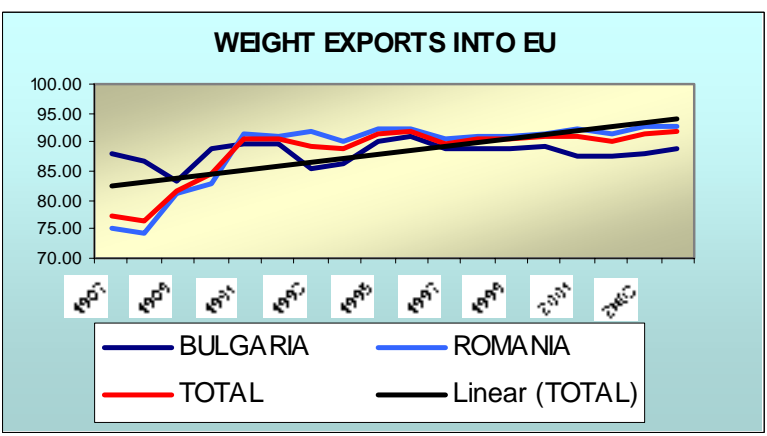

The weight of exports towards EU 


\section{Graph no 3: Sector-based exports of Romania (in \%)}
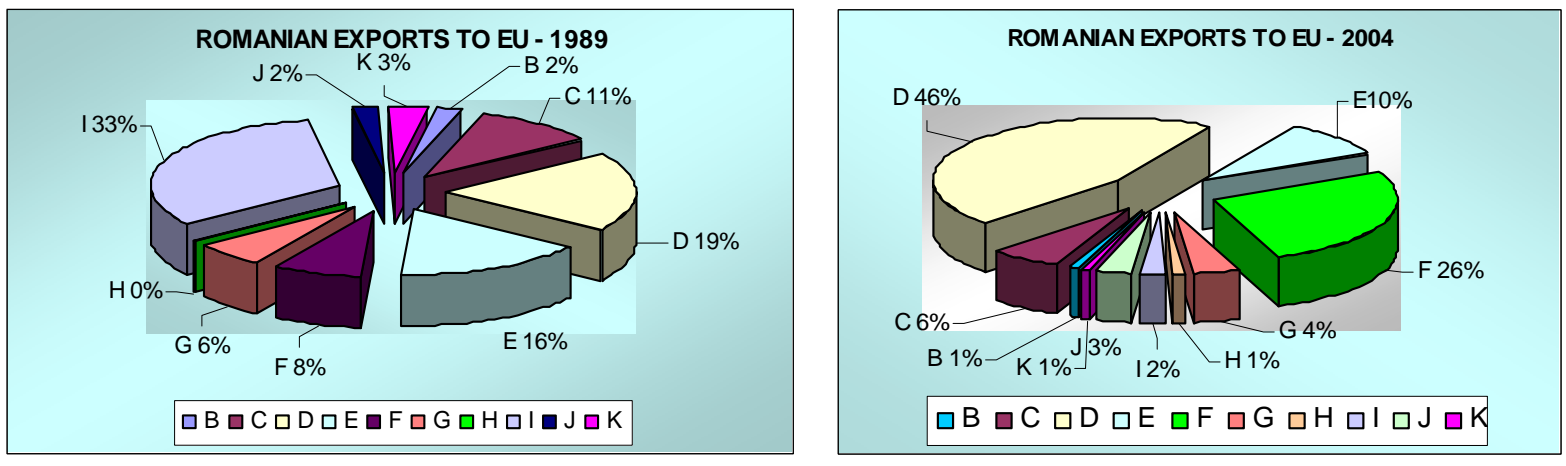

notes:

\begin{tabular}{|l|l|l|l|}
\hline Code & Sector & Code & Sector \\
\hline B & Building materials & G & Chemistry \\
\hline C & Iron industry, metal industry & H & Minerais \\
\hline D & Textiles, leathers & I & Energy \\
\hline E & Woods, leathers & J & Agriculture \\
\hline F & Electric, mechanics & K & Foodstuffs \\
\hline
\end{tabular}

Concerning the structure of Romania trade with EU countries, we can observe evolutions towards industry reallocation. In 1989, Romania exported products of the energy sector (33\%), textiles (19\%), wood paper (16\%), mechanic electric (8\%), chemistry (6\%), and produced building materials, agricultural and food (2.3\%). In 2004, statistical examination confirms our intuition of specialization in sectors where the labor factor comparative advantage has a key role. Therefore, reallocations are concentrated essentially in the textile sector reaching $46 \%$ (in 2004) comparatively with $19 \%$ (in 1989), followed by the mechanic electric sector reaching 26\% (in 2004) compared to 8\% (in 1989), a sector where segments of production resting on assembly operations were particularly developed. With regard to the other sectors, one can note a continuous decreasing level of exports. There have been reductions in 2004 compared to 1989, for the sector of iron and steel industry from $11 \%$ to $6 \%$, for the energy sector from $33 \%$ to $3 \%$, for the drink and paper sectors from $16 \%$ to $10 \%$ (due to the fall of paper production), for the chemistry sector from $6 \%$ to $4 \%$, followed by agricultural products from of $2 \%$ to $1 \%$ and food products from $3 \%$ to $1 \%$.

A similar evolution can also be observed in Bulgaria where the textile sector has increased by $13 \%$ (in 1989 ) to $36 \%$ (in 2004), the iron and steel industry sectors from $11 \%$ to $21 \%$, and the electric and mechanic sectors from $14 \%$ to $17 \%$. In the other sectors there has been a fall of the export levels of about $1 \%$ in 2004. This situation puts in evidence a strengthening of the specialization process with a positive impact on complementary specialization. However, the production development of these low added value sectors cannot lead to a convergence improvement, but on the contrary entails a strengthening of the divergence between developed and the less developed. 


\section{Graph $n^{\circ}$ 4: Sector-based exports of Bulgaria (in \%)}
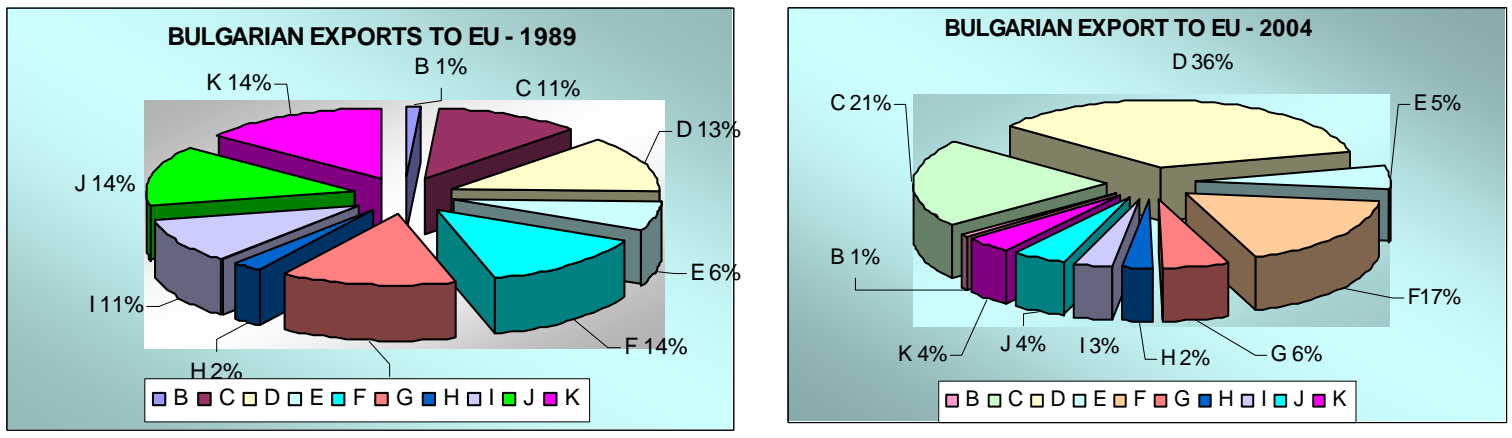

Graph no 5: Weight of exports to EU from OECD - 19

\begin{tabular}{|c|c|c|c|c|}
\hline & & & $\begin{array}{c}\text { Romania } \\
\text { and }\end{array}$ & WEGHT EXPORTS INTO EU \\
\hline Year & Bulgaria & Romania & Bulgaria & 100.00 \\
\hline 1987 & 87.96 & 75.32 & 77.25 & 90.00 \\
\hline 1988 & 86.78 & 74.39 & 76.34 & 85.00 \\
\hline 1989 & 83.27 & 81.24 & 81.60 & $\begin{array}{l}80.00 \\
75.00\end{array}=$ \\
\hline 1990 & 88.89 & 82.82 & 84.43 & 70.00 \\
\hline 1991 & 89.52 & 91.39 & 90.76 & مी \\
\hline 1992 & 89.79 & 90.82 & 90.42 & BULGARIA $\quad$ ROMANIA \\
\hline 1993 & 85.32 & 91.90 & 89.40 & 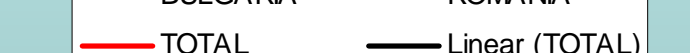 \\
\hline 1994 & 86.13 & 90.12 & 88.70 & 一IOIAL $\quad$ LInear (IOIAL) \\
\hline 1995 & 90.00 & 92.43 & 91.57 & \\
\hline 1996 & 91.14 & 92.50 & 92.06 & \\
\hline 1997 & 88.93 & 90.36 & 89.91 & \\
\hline 1998 & 88.82 & 91.05 & 90.38 & \\
\hline 1999 & 88.96 & 91.11 & 90.52 & \\
\hline 2000 & 89.26 & 91.60 & 90.93 & \\
\hline 2001 & 87.44 & 92.41 & 91.03 & \\
\hline 2002 & 87.50 & 91.28 & 90.30 & \\
\hline 2003 & 87.99 & 92.58 & 91.38 & \\
\hline 2004 & 88.87 & 92.79 & 91.75 & \\
\hline
\end{tabular}

